\title{
INVESTIGATION OF DISSOLUTION KINETICS OF A NIGERIAN COLUMBITE IN HYDROFLUORIC ACID USING THE SHRINKING CORE MODEL
}

\author{
0. Sanda ${ }^{1, *}$ and E. A. Taiwo ${ }^{2}$ \\ 1,2 Department of Chemical Engineering, Obafemi AWolowo University, Ile-IFe, OSUn STate NiGERIA. \\ E-mail addresses: ${ }^{1}$ osanda@oauife.edu.ng, ${ }^{2}$ etaiwo@yahoo.com
}

\begin{abstract}
A study of the kinetics of the dissolution of a Nigerian columbite in hydrofluoric acid has been examined and an investigation on the quantitative leaching of the mineral was also carried out. The effects of some parameters such as acid concentration, contact time and temperature were investigated. Elemental analysis of the ore was done using Particle-induced X-ray Emission (PIXE) spectroscopy with $2.5 \mathrm{MeV}$ protons and this showed the major elements in the ore to be Si (8.82\%), Fe (10.74\%), Mn (4.72\%), Ta (6.80\%), Nb (28.90\%) and W(2.61\%), with K, $\mathrm{Ni}, \mathrm{Zn}, \mathrm{Sr}$ and $Y$ occurring in traces. Experimental results indicate that the dissolution rate is chemical reaction controlled, with reaction order of 0.57. Dissolution of over $90 \%$ of the columbite was achieved in $5 \mathrm{~h}$, using $20 \mathrm{M}$ $H F$ at $90^{\circ} \mathrm{C}$ with $100 \mu \mathrm{m}$ particle sizes. Activation energy, $E_{a}$ of $15.70 \mathrm{KJ} \cdot \mathrm{mole}^{-1}$ was obtained for the process.
\end{abstract}

Keywords: columbite, tantalum, leaching, shrinking core model, PIXE

\section{INTRODUCTION}

Tantalite-columbite and tantalite concentrates are comprised of an isomorphous series of tantalite minerals which are chemically stable and have a general chemical formula of $(\mathrm{Fe}, \mathrm{Mn})(\mathrm{Nb}, \mathrm{Ta})_{2} \mathrm{O}_{5}$. The concentrates have a variable composition with respect to iron, manganese, niobium and tantalum, but these generally have a combined niobium-tantalum content of about 50 to 60 percent [1].The mineral is referred to as tantalite if it contains a higher proportion of $\mathrm{FeTa}_{2} \mathrm{O}_{6}$ (or $\mathrm{MnTa}_{2} \mathrm{O}_{6}$ ) than $\mathrm{FeNb}_{2} \mathrm{O}_{6}$ (or $\mathrm{MnNb}_{2} \mathrm{O}_{6}$ ) and is referred to as columbite, if otherwise. The ore in addition to the tantalite mineral contains other "non-tantalite" materials which accounts for the variable composition. Tantalite-columbite minerals are not readily attacked by most mineral acids, except hydrofluoric acid, or a mixture of hydrofluoric and other mineral acids such as sulphuric acid.

Niobium/tantalum bearing minerals are mined in Australia, Brazil, Canada, China, Nigeria, Ethiopia and Mozambique [2,3]. Columbite and various niobiumbearing minerals are widespread in the pan-African basement of Nigeria with the tantalite-columbite reserves spreads across ten states in comprising Niger, Nassarawa, Oyo, Kaduna, Kogi, Kwara, Gombe,
Zamfara, Ekiti and the Federal Capital Territory (FCT) $[4,5]$.

Several works have been carried out on the mineralogical and compositional characterisation of major tantalum bearing mineral deposits in the country [6 - 8]. These works revealed the extensive abundance of elemental tantalum in association with niobium. The mineralogical characterisation of tantalite from selected parts of Nigeria revealed that the niobium constituents in the deposits studied ranges from $20 \%$ to39 \%, indicating that the deposits in Nigeria contain ores of economic value with respect to their niobium content and are amenable to hydrometallurgical processing [8].

The objective of this work is to study the leaching kinetics of Nigerian columbite in hydrofluoric acid under different conditions in other to facilitate the eventual recovery of the niobium values by solvent extraction.

\section{THEORY}

The Shrinking Core Model (SCM) was developed by Yagi and Kunii [9 - 11] originally for gas-solid combustion system, but has been successfully applied to non-combustion systems involving liquids and solids [12 - 14]. 
The SCM is based on the following assumptions [13, 15]:

- The particles are spherical.

- During the process, the particle shrinks uniformly, thus, it maintains its spherical shape.

- In the absence of adequate information, the thickness of the layer around the core was assumed constant during the leaching process.

- The temperature remains constant during the process.

Considering the assumptions above, the rate of reaction per unit surface of the core can be related to the dissolution rate of the solute of interest is expressed as follows [15]:

$$
R=-\frac{M}{S_{e}} \frac{d N}{d t}
$$

where $\mathrm{M}$ and $\mathrm{N}$ are the molar mass of the solute and the amount (in moles) of the solute present in the solid, respectively and $S_{e}$ is the surface area of the unreacted solid. Since the particles are assumed to be spherical, equation (1) can written as:

$$
R=-\frac{M}{\left(4 \pi r_{t}^{2}\right)} \frac{d}{d t}\left(\frac{4 \pi r_{t}^{3} \rho}{3 M}\right)
$$

where $\rho$ is the particle density and $r_{t}$ is the radius of the unreacted solid at any time ( $t>0)$, respectively.

If the progress of the reaction is unaffected by the presence of a product (or "ash") layer, the reaction is said to be chemical reaction controlled. If the dissolution is assumed to be a first order reaction, (2) becomes [16]:

$$
\frac{d N}{d t}=\omega \rho \frac{d r_{c}}{d t}=k^{\prime \prime} C_{A}
$$

where $\mathrm{k}^{\prime \prime}$ and $\mathrm{C}_{\mathrm{A}}$ are the mass transfer coefficient between fluid and particle, and the concentration of the reactant in the reacting fluid respectively. Solving (3) gives

$$
t=\frac{\omega \rho r_{i}}{k^{\prime \prime} C_{A}}\left[1-\frac{r_{t}}{r_{i}}\right]
$$

where $r_{i}$ is the initial radius of the unreacted solid and $\omega$ is the mass fraction of the solute in the bulk solid. $k^{\prime \prime}$ is the first-order rate constant for the surface reaction. Taking $k_{r}=\frac{\boldsymbol{k}^{\prime \prime} c_{A}}{\omega \rho r_{i}}$ where $k_{r}$ is the "apparent" rate constant, (4) becomes [16]:

$$
k_{r} t=1-(1-X)^{\frac{1}{3}}
$$

where $\mathrm{X}$ is the fractional conversion, and

$$
\begin{gathered}
1-X=\frac{\text { mass of unreacted core at time t }}{\text { initial mass of particle }}=\frac{\frac{4}{3} \pi r_{t}^{3} \rho}{\frac{4}{3} \pi r_{i}^{3} \rho} \\
=\left(\frac{r_{t}}{r_{i}}\right)^{3}
\end{gathered}
$$

It is noteworthy that the time required for complete conversion in this case is the reciprocal of the "apparent" rate constant [16].

In many cases, the rate-determining step is the resistance offered by the solid product or gangue layer. In this case, equation (1) is written as[16]:

$$
-\frac{1}{S_{e}} \frac{d N}{d t}=\mathcal{D}_{e} \frac{d C_{A}}{d r}
$$

where $\mathcal{D}_{e}$ is the effective diffusivity.

Solving equation (7) gives the relation for the Shrinking Core Model with product layer controlling the reaction kinetics $[16,17]$ :

$$
1-3(1-X)^{\frac{2}{3}}+2(1-X)=k_{r} t
$$

$$
\text { with } k_{r}=\frac{6 \mathcal{D}_{e} C_{A}}{\omega \rho r_{i}^{2}} \text {. }
$$

\section{EXPERIMENTAL}

The columbite used for this investigation was sourced from Wambe-Nassarawa field in Nassarawa State of Nigeria. The elemental analysis of the columbite mineral was determined by particle induced X-ray emission (PIXE) analysis using $2.5 \mathrm{MeV}$ protons from a 1.7 MV Tandem Accelerator. The charge and the current used in the analysis were $0.5 \mu \mathrm{C}$ and $0.26 \mathrm{nA}$ respectively and the spectrum obtained were analysed using the Gupixwin software, v 2.1.

Analar grade HF was used in this work and doubly distilled water was used in the preparation of all solutions. Due to the corrosive action of HF on glass, thick-walled polypropylene containers were used as reaction and storage vessels in this work.

The ore was milled to $100 \mu \mathrm{m}$ using a Rocklabs ring mill. The dissolution was carried out using $5 \mathrm{~g}$ of the milled ore in HF concentrations varying from $5-20$ mol.dm ${ }^{-3}$ at reaction temperatures and times ranging from $30-90{ }^{\circ} \mathrm{C}$ and $1-5 \mathrm{~h}$ respectively. The dissolution was carried out in well covered polypropylene bottles with $50 \mathrm{ml}$ of the hydrofluoric acid solution used per batch. For experimental runs involving elevated temperatures, the heating was done using a thermostatic water bath. To ensure proper mixing of the reaction mixture, the reaction vessels were shaken at $5 \mathrm{~min}$ intervals. Considering the toxic nature of HF vapour, all experimental runs were carried out in a fume chamber.

At the end of each run, the mixture was filtered and the residue was washed using distilled water to get rid of residual $\mathrm{HF}$, dried in an oven at $105^{\circ} \mathrm{C}$ for $3 \mathrm{~h}$ and weighed. The extent of dissolution was determined by the formula: 


$$
X=\frac{W_{o}-W_{f}}{W_{o}}
$$

In (9), $W_{o}$ is the initial mass of the sample, $g, W_{f}$ is the final mass (or mass of residue), $\mathrm{g}, X$ is the mass fraction of ore dissolved. A plot of $X$ against time for each acid concentration and temperature gives a picture of how these parameters affect the extent of ore dissolution and can be of use when developing a model which describes the dissolution process.

\section{RESULTS AND DISCUSSION}

\subsection{Elemental Analysis}

The PIXE spectrum shown in Fig. 1 shows the major constituents of the ore to be silicon (8.82\%), iron (10.74\%), tantalum (6.80\%), niobium (28.90\%), titanium (3.75\%), tungsten (2.61\%) and manganese (4.72\%), with, potassium, zirconium, vanadium, nickel, zinc, strontium, and ytterbium occurring in traces. The result of the elemental analysis is presented in Table 1. As shown in Table 1, the constituents do not add up to $100 \%$. The reason for this is that the analytical technique used (that is, PIXE) is suited for elements with atomic numbers greater than 18. Components such as silica, alumina, and oxygen (from oxides) which are common to most mineral ores are usually not reported by this technique, and should account for the deficit observed here. In addition, the detector commonly used for PIXE is silicon based [19] and might not detect silica. Since there is no peak for silicon in Fig. 1, the "silicon" reported in Table 1 might be from the detector and not from the sample itself.
Table 1: Elemental composition of the columbite used

\begin{tabular}{cc}
\hline Element & Concentration (wt. \%) \\
\hline $\mathrm{Si}$ & 8.83 \\
$\mathrm{~K}$ & 0.04 \\
$\mathrm{Ca}$ & 0.10 \\
$\mathrm{Ti}$ & 3.75 \\
$\mathrm{Mn}$ & 4.72 \\
$\mathrm{Fe}$ & 10.74 \\
$\mathrm{Ni}$ & 0.003 \\
$\mathrm{Zn}$ & 0.03 \\
$\mathrm{Sr}$ & 0.009 \\
$\mathrm{Y}$ & 0.002 \\
$\mathrm{Zr}$ & 0.27 \\
$\mathrm{Nb}$ & 28.90 \\
$\mathrm{Sn}$ & 0.93 \\
$\mathrm{Ta}$ & 6.80 \\
$\mathrm{~W}$ & 2.61 \\
$\mathrm{U}$ & 0.78 \\
\hline
\end{tabular}

\subsection{Effect of Acid Concentration}

The results obtained as seen in Fig. 2, showed that the rate of dissolution is affected directly by the concentration of the acid. The rate of dissolution of the columbite was observed to increase with increasing HF concentration.

To determine the order of the dissolution, equations (4) and (6) were used to test the results obtained from the dissolution. The assumption is that the dissolution of the ore in hydrofluoric acid is either chemical reaction controlled or ash/products layer diffusion controlled.

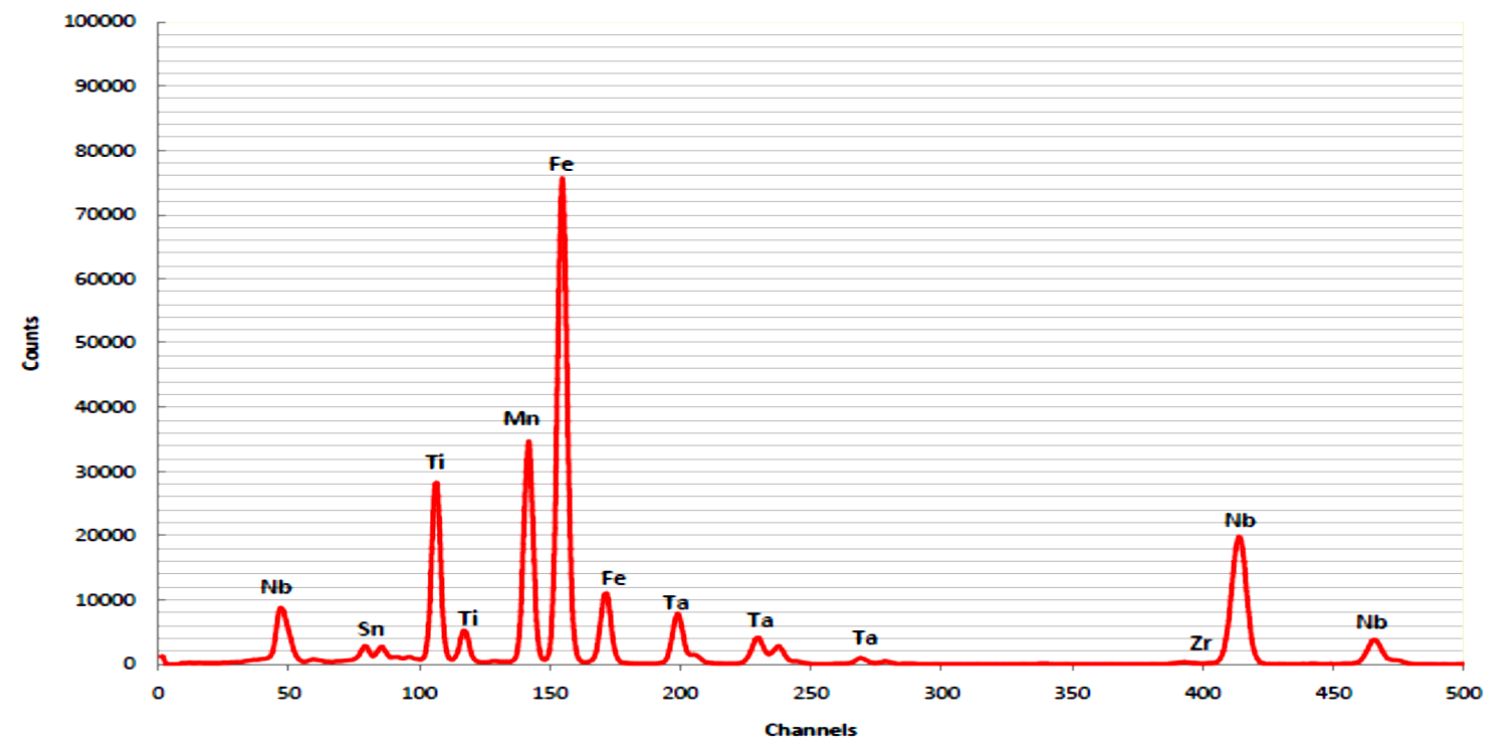

Figure 1: PIXE spectrum of the columbite showing the major elements present 
Comparing the data obtained using $20 \mathrm{M}$ hydrofluoric acid for the two models, the deviation from linearity is more pronounced for the ash layer diffusion model as shown in Table 2, indicating that the predominant rate controlling mechanism is chemical reaction. This result is comparable with what has been reported by various authors $[15,17,18]$.

The results obtained from the dissolution showed that the dissolution followed the Shrinking Core Model (SCM) with chemical reaction as the rate controlling step as shown by the plots in Fig. 3. The apparent rate constants $\left(k_{r}\right)$ obtained from Fig. 3 can be related to the acid concentration $\left[\mathrm{H}^{+}\right]$by the relation presented in equation (8):

$$
k_{r}=a\left[H^{+}\right]^{b}
$$

Where $b$ is the order of the reaction and $a$ is a constant which depends on the system under consideration. A plot of $k_{r}$ against $\left.\mathrm{H}^{+}\right]$(Fig. 4) gave the order of the reaction to be 0.57 , which is similar to the values reported in other works on similar systems $[4,17,18]$.

\subsection{Effect of temperature}

From Figures 2 and 3, it can be deduced that the dissolution of columbite in hydrofluoric acid is predominantly chemical reactions controlled, with the apparent rate constants $k_{r}$ shown in Table 3 . The dissolution model in mathematical form can be written as shown below:

$$
1-(1-X)^{\frac{1}{3}}=k_{o} \exp \left(\frac{E_{a}}{R T}\right) \cdot t
$$

Where

$$
k_{r}=k_{o} \exp \left(\frac{E_{a}}{R T}\right)
$$

$\mathrm{R}$ is the universal gas constant in $\mathrm{KJ} \cdot \mathrm{mol}^{-1}, \mathrm{E}_{\mathrm{a}}$ is the activation energy and $\mathrm{T}$ is the temperature in Kelvins. Equation (10) can be written in logarithmic form:

$$
\ln k_{r}=\ln k_{o}+\left(\frac{E_{a}}{R}\right) \cdot \frac{1}{T}
$$

From the plot of $\ln k_{r}$ against $\frac{1}{T}$ for columbite dissolution using $20 \mathrm{M} \mathrm{HF}$ (Fig. 5), the activation energy $E_{a}$ was found to be $15.7 \mathrm{KJ} \cdot \mathrm{mol}^{-1}$
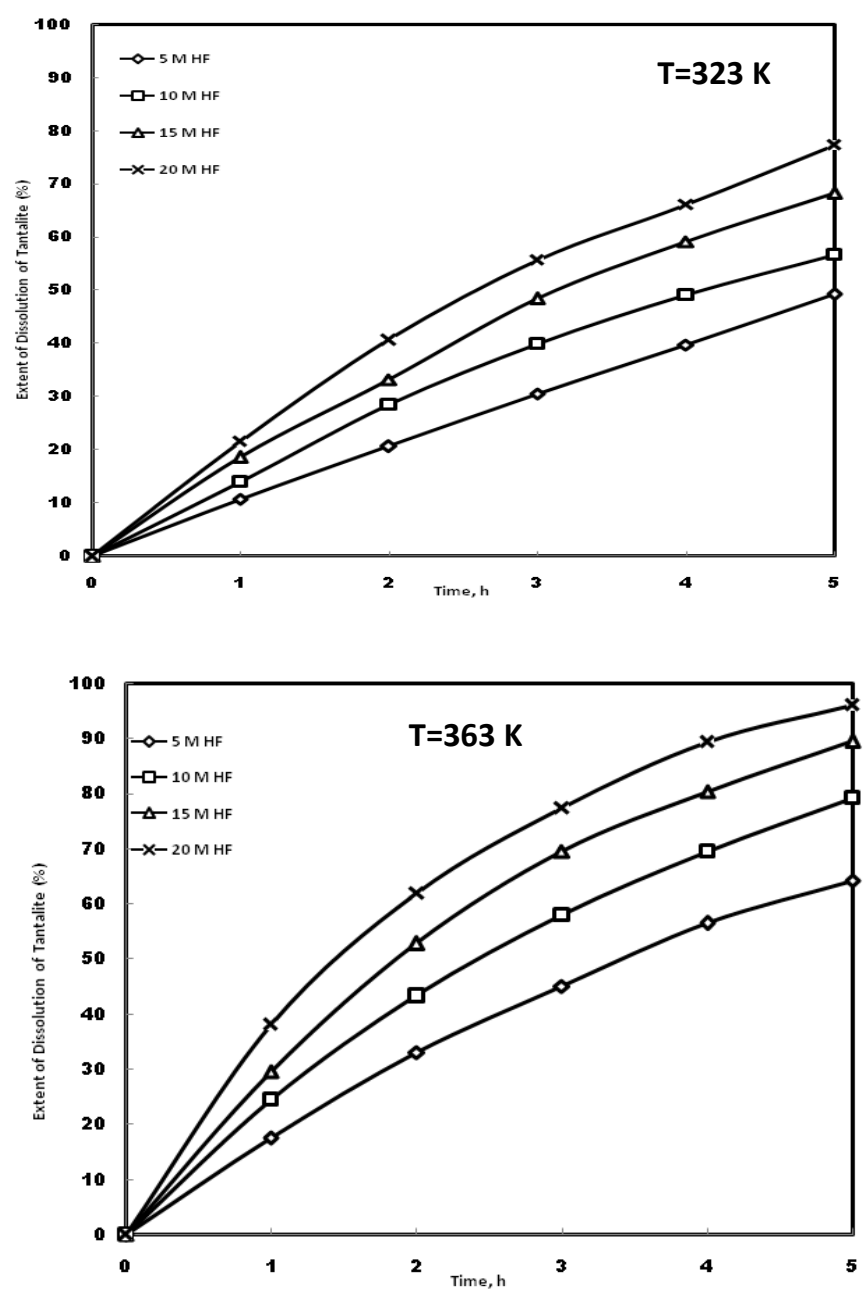
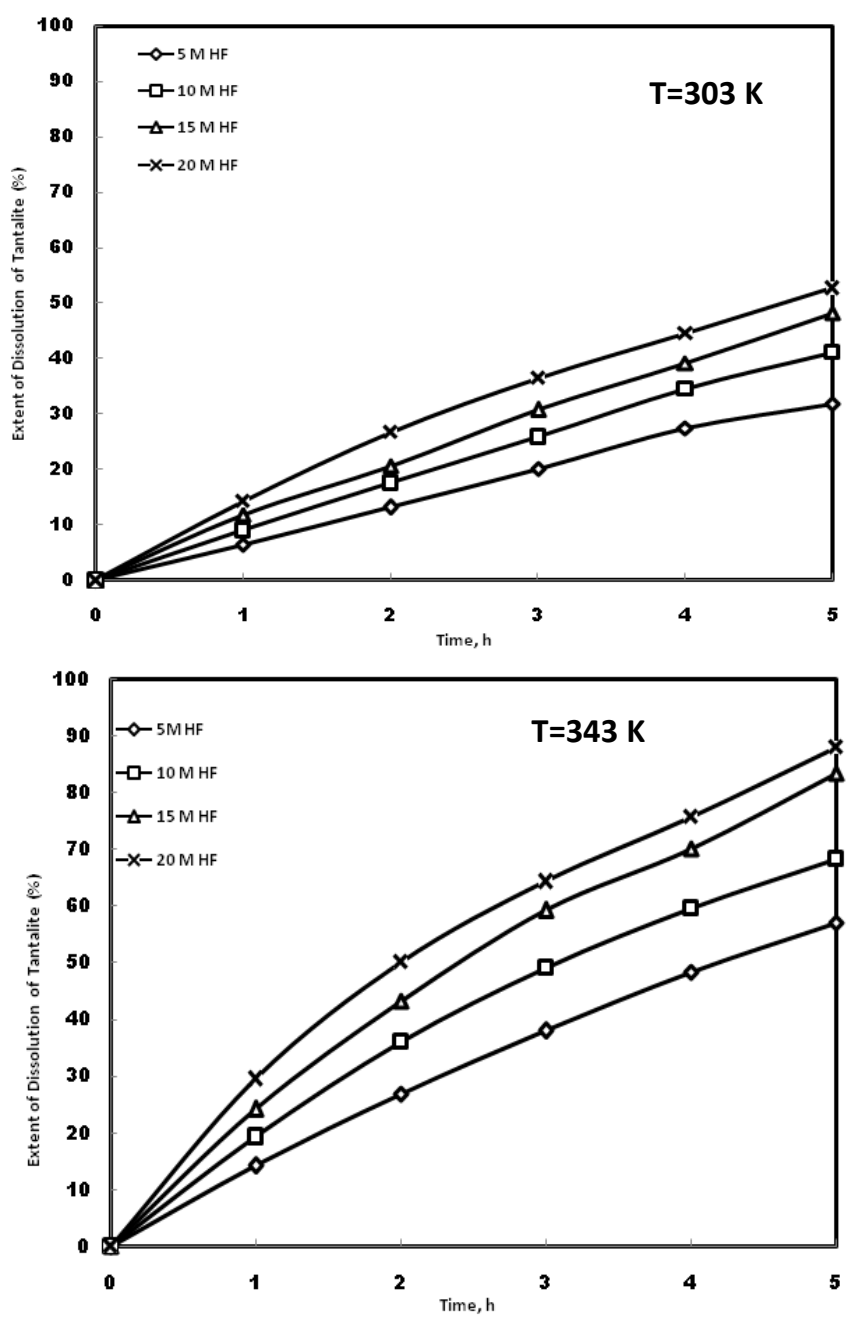

Figure 2: Extent of dissolution of columbite at various temperatures and acid concentrations 
Table 2: comparison of the rate constants and correlation fit for both models considered for $20 \mathrm{M} \mathrm{HF}$

\begin{tabular}{ccccc}
\hline \multirow{2}{*}{$\begin{array}{c}\text { Temperature, } \mathrm{T} \\
(\mathrm{K})\end{array}$} & \multicolumn{2}{c}{ Apparent rate constants $\left(k_{r}, \mathrm{~h}^{-1}\right)$} & \multicolumn{2}{c}{ Correlation coefficients $\left(\mathrm{R}^{2}\right)$} \\
\cline { 2 - 5 } & $\begin{array}{c}\text { Chemical reaction } \\
\text { controlled }\end{array}$ & $\begin{array}{c}\text { Ash/product diffusion } \\
\text { controlled }\end{array}$ & $\begin{array}{c}\text { Chemical reaction } \\
\text { controlled }\end{array}$ & $\begin{array}{c}\text { Ash/product diffusion } \\
\text { controlled }\end{array}$ \\
\hline 303 & 0.045 & 0.009 & 0.995 & 0.914 \\
323 & 0.077 & 0.012 & 0.998 & 0.922 \\
343 & 0.098 & 0.022 & 0.995 & 0.942 \\
363 & 0.132 & 0.040 & 0.997 & 0.975 \\
\hline
\end{tabular}

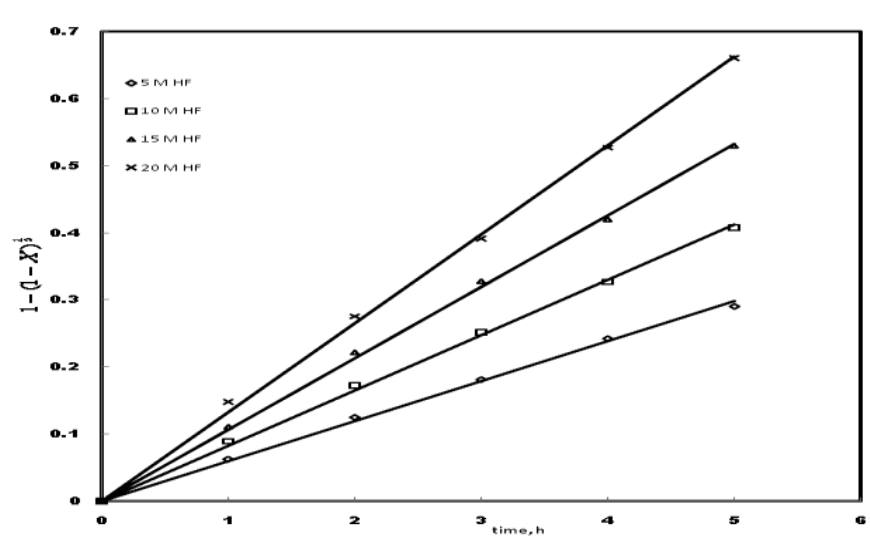

Figure 3: Plot of $1-(1-X)^{\frac{1}{3}}$ against contact time at 363 $K$

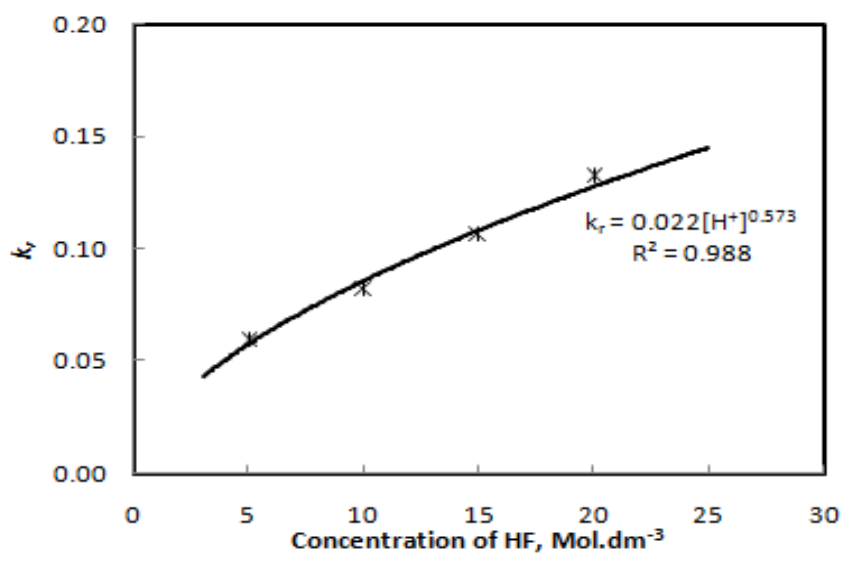

Figure 4: Plot of $k_{r}$ against acid concentration at $363 \mathrm{~K}$

Table 3: Variations in apparent rate constants with temperature

\begin{tabular}{cc}
\hline $\begin{array}{c}\text { Temperature, } \mathrm{T} \\
(\mathrm{K})\end{array}$ & $k_{r}$ values for dissolution in 20 M HF, \\
$\mathrm{h}^{-1}$
\end{tabular}

The pre-exponential term $\mathrm{k}_{\mathrm{o}}$ varies for each dissolution system and for $20 \mathrm{M} \mathrm{HF}$, equation (11) can be written in the form

$$
1-(1-X)^{\frac{1}{3}}=\left(6.68 \times 10^{-3}\right) \exp \left(\frac{15700}{R T}\right)
$$

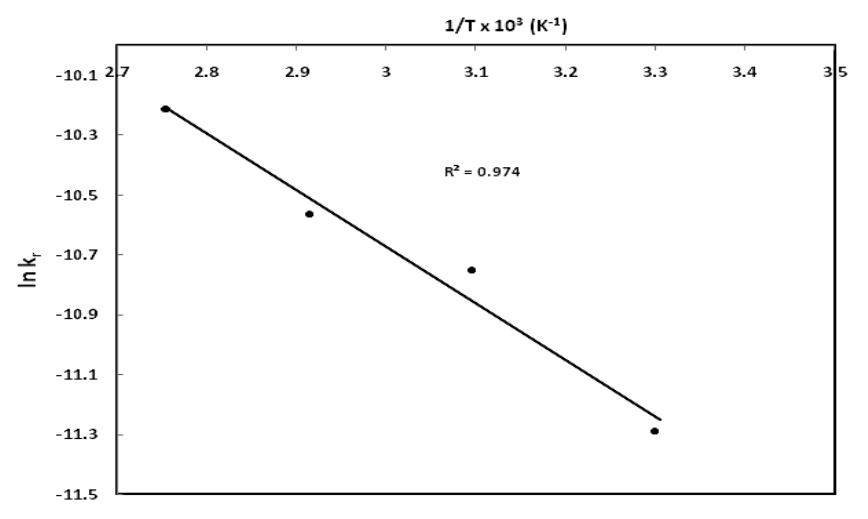

Figure 5: Arrhenius plot for columbite dissolution in $20 \mathrm{MHF}$

\section{CONCLUSIONS}

In this study, the dissolution kinetics of columbite in hydrofluoric acid was examined. The results showed that the reaction rate increases with acid concentration and reaction temperature. The dissolution kinetics was found to be governed by the shrinking core model with chemical reaction as the rate-controlling mechanism. The reaction order with respect to $\left[\mathrm{H}^{+}\right]$was found to be 0.57 and a value of $15.70 \mathrm{KJ} . \mathrm{mol}^{-1}$ was obtained as activation energy $\left(E_{a}\right)$, for the dissolution process.

\section{REFERENCES}

[1] Gupta, C. K. and Suri, A. K. "Extractive Metallurgy of Niobium". CRC Press, Boca Raton, Florida, U.S.A, 1994

[2] TIC "Tantalum: Raw Materials and Processing". http://www.tanb.org/tantalum1.html Accessed August 12, 2010.

[3] TIC "Niobium: Raw Materials and Processing". http://www.tanb.org/niobium1.htmlAccessed August 12, 2010.

[4] Baba, A. A., Adekola, F. A., Dele-Ige, O. I. and Bale, R. B. "Investigation of Dissolution Kinetics of A Nigerian Tantalite Ore in Nitric Acid". Journal of Minerals \& Materials Characterization and Engineering, vol. 7, Number 1, ,pp 83-95, 2007.

[5] NGSA "Tantalite".http://www.ngsang.org/tantalite.pdf. Accessed March 2, 2010. 
[6] Funtua, I. I. "Analysis of $\mathrm{Nb}$-Ta ores by Energy Dispersive X-ray Flourescence Spectroscopy". Journal of Trace Microprobe Techniques, vol. 17, Number 2, 1999, pp. 89-95

[7] Obianjunwa, E. I. "Analysis of some Nigerian Solid Mineral ores by Energy Dispersive X-ray Fluorescence Spectroscopy". Nuclear Instruments and Methods in Physics Research B, vol. 184, ,pp 430-437. 2001.

[8] Adetunji, A. R., Sinyanbola, W. O., Funtua, I. I., Olusunle, S. O. O., Afonja, A. A. and Adewoye, 0. 0. "Assessment of Beneficiation Routes of Tantalite Ores from Key Locations in Nigeria". Journal of Minerals and Materials Characterization and Engineering, vol. 4, Number 2, 2005, pp 67-73.

[9] Yagi, S. and Kunii, D. "Fluidized-solids reactors with continuous solids feed-I: Residence time of particles in fluidized beds". Chemical Engineering Science, vol. 16, Number 3-4, pp 364-371. 1961.

[10] Yagi, S. and Kunii, D. "Fluidized-solids reactors with continuous solids feed-II: Conversion for overflow and carryover particles". Chemical Engineering Science, vol. 16, Number 3-4, , pp 372-379. 1961.

[11] Yagi, S. and Kunii, D. "Fluidized-solids reactors with continuous solids feed-III : Conversion in experimental fluidized-solids reactors". Chemical Engineering Science, vol. 16, Number 3-4, , pp 380 391, 1961.

[12] Lindman, N. and Simonsson, D. "On the application of the shrinking core model to liquid-solid reactions". Chemical Engineering Science, vol. 34, Number 1, , pp 31-35, 1979.

[13] Liddell, K. C. "Shrinking core models in hydrometallurgy: What students are not being told about the pseudo-steady approximation", Hydrometallurgy vol. 79, pp 62-68. 2005.

[14] Souza, A. D., Peina, P. S., Lima, E. V. O., daSilva, C. A. and Leão, V. A. "Kinetics of sulphuric acid leaching of a zinc silicate calcine". Hydrometallurgy vol. 89, , pp 337-345. 2007.

[15] Safari, V., Arzpeyma G., Rashchi F. and Mostoufi N. "A shrinking particle-shrinking core model for leaching of a zinc ore containing silica". International Journal of Mineral Processing, Vol. 93, Issue 1, pp 79-83, 2009.

[16] Levenspiel 0. "Chemical Reaction Engineering", 3ed. John Wiley and Sons, New York, 1999.

[17] Baba, A. A., Adekola, F. A. and Folashade, A. 0. "Quantitative leaching of a Nigerian Iron ore in hydrochloric acid". Journal of Applied Sciences and Environmental Management.Vol. 9, Number 1, ,pp 15-20. 2005

[18] Aydogan S., Aras A. and Cambazoglu M. "Dissolution kinetics of sphalerite in acidic ferric chloride leaching". Chemical Engineering Journal. Vol. 114, pp 67-72. 2005.

[19] Rodríguez-Fernández L., Miranda J., and Oliver A. Characterization of a $\mathrm{Si}(\mathrm{Li})$ detector for PIXE analysis. Journal of X-Ray Science and Technology. Vol4, Number 3, 1994, pp 221-246, 1994. 